\title{
ADESÃO AOS MEDICAMENTOS GENÉRICOS: VERIFICAÇÃO PRELIMINAR APÓS SETE ANOS DE IMPLANTAÇÃO DA LEI
}

\section{VERIFICATION OF THE ADHESION OF A COMMUNITY TO GENERIC MEDICINES AFTER SEVEN YEARS OF IMPLANTATION OF THE LAW}

\author{
MÁRCIA FÁTIMA KERKHOFF UTZIG ${ }^{1}$, SUZANE VIRTUOSO ${ }^{2}$, SIMONE MARIA \\ MENEGATTI DE OLIVEIRA ${ }^{2}$.
}

\author{
1. Discente de Especialização em Farmacologia Aplicada da UNIOESTE - PR \\ Email: simone_meneoli@yahoo.com.br \\ 2. Docente do Curso de Farmácia da UNIOESTE - PR
}

REC: 08/09 AC: 09/09

\begin{abstract}
RESUMO :
A adoção de uma política de medicamentos genéricos surgiu com a Lei 9.787/99, por questões sociais de dificuldade de acesso da população aos medicamentos com menor custo e de boa qualidade. Baseado na experiência e na regulamentação técnica sobre genéricos em outros países, a legislação brasileira exige destes a bioequivalência e biodisponibilidade iguais às do medicamento de referência. Este trabalho visou avaliar a adesão à política de medicamentos genéricos, no período de sete anos, por parte da população e dos profissionais de saúde; especialmente a classe médica. Concluiu-se que houve adesão da população à política de medicamentos genéricos, porém há necessidade de maior divulgação, entre os profissionais da saúde, sobretudo prescritores, da necessidade e dos reais ganhos da população com uma efetiva política de genéricos.
\end{abstract}

Palavras-chave: Medicamento genérico; Política de medicamentos, Prescrição.

\begin{abstract}
:
The adoption of a politic of generic drugs began with the Law 9.787/99, of the social issues of difficulty of access to medicines for people with lower cost and good quality. Based on the experience and technical regulations on generics in other countries, the Brazilian law requires them to bioequivalence and bioavailability of the drug equal to the reference. This study aimed to evaluate the adherence to the policy of generic drugs in the period of seven years by the population and health professionals, especially the medical profession. It was concluded that the population was adhered to the politic of generic drugs, but there is a need for wider dissemination among health professionals, especially prescribers, and the need of real earnings of the population with an effective policy on generics.
\end{abstract}

Keywords: Generic drug; politic of drugs, prescription.

\section{INTRODUÇÃO}

No Brasil, a discussão sobre o medicamento genérico teve início com a Lei 9.787 de 10 de fevereiro de 1999, conhecida como Lei dos Genéricos, a qual instituiu o medicamento genérico no Brasil, pondo fim a uma polêmica que se arrastou por quase uma década (BRASIL, 1999).

A promoção do uso racional dos medicamentos tem sido também uma das prin- 
cipais diretrizes preconizadas pela Organização Mundial de Saúde, com o objetivo de orientar as políticas nacionais para a utilização correta dos produtos farmacêuticos. Para isto, é fundamental a participação ativa e consciente dos profissionais responsáveis pela prescrição e dispensação de medicamentos (médicos, odontólogos e farmacêuticos), além da ampla disseminação junto à população de informações corretas, por parte de todos os profissionais de saúde (CREMESP \& CRF-SP, 2001).

A maioria dos medicamentos disponíveis no mercado é comercializada pela marca. O que diferencia os medicamentos genéricos é que eles são comercializados pelo nome do princípio ativo e tem impresso, nas embalagens, uma tarja amarela com a letra "G" em destaque e os dizeres: .Medicamento Genérico - Lei 9.787/99. (BRASIL, 2001).

A indústria de medicamentos genéricos teve origem na década de 60 , por iniciativa do governo dos Estados Unidos - primeiro país a adotar essa política - onde os medicamentos genéricos representam atualmente $72 \%$ do receituário médico e entram no mercado, em média, três meses após expiração da patente. Posteriormente, muitos países da Europa também adotaram a Política dos Genéricos. Os genéricos são bem aceitos nos Estados Unidos, Canadá, Dinamarca, Alemanha, Grã-Bretanha e Holanda. Estados Unidos, Japão e Alemanha representam $60 \%$ do mercado mundial de genéricos (ANVISA, 2002).

Segundo Vieira e Zucchi (2006) em seu estudo sobre a diferença de preço do genérico no seu lançamento em relação ao medicamento de referência, verificou-se que $99 \%$ dos genéricos tinham preço menor do que o de referência. Conforme dados da Associação Brasileira de Redes de Farmácias (Abrafarma), a venda de genéricos no país aumentou $16,6 \%$ em 2005 , comparado a 2004 . No ano de 2005 , os genéricos movimentaram $\mathrm{R} \$ 529,6$ mil, correspondendo a $11,06 \%$ da venda total de medicamentos (PIACENTINI, 2006).

Conforme RDC n 84, de 19 de março de 2002, no sistema único de saúde, os medicamentos prescritos pelo profissional devem ser descritos obrigatoriamente conforme a Denominação Comum Brasileira (DCB) e nos serviços privados de saúde pode ser o nome genérico ou comercial. No caso da não intercambialidade pelo prescritor esta deve ser feita de próprio punho e de forma legível. No momento da dispensação é permitida ao farmacêutico a substituição do medicamento prescrito, exclusivamente, pelo medicamento genérico correspondente, através de carimbo com nome e número de inscrição no Conselho Regional de Farmácia, data e assinatura (BRASIL, 2002). Para isso os profissionais da área da saúde como médicos e odontólogos precisam estar preparados para prescrever, e principalmente os farmacêuticos, por serem os profissionais do medicamento, estarem aptos para esclarecer dúvidas em relação ao preço, posologia, tratamento, interações e reações. Assim, a população assistida por estes profissionais teria melhor adesão ao tratamento e conseqüentemente, melhores resultados, diminuindo consideravelmente os

problemas da saúde pública (MENDA, 2002).

Segundo dados do Ministério da Saúde, o projeto de produção de genéricos permitiu uma redução de $20 \%$ nos gastos com aquisição de medicamentos por parte do governo. A possibilidade de se produzir medicamentos com os mesmos princípios ativos daqueles identificados pela marca comercial com qualidade atestada pelo Ministério da Saúde, por empresas outras que não só as grandes multinacionais, elevou 
o grau de competitividade no segmento. Essa competitividade trouxe os preços para baixo, mesmo dos medicamentos originais. A nova gama de opções possibilita uma escolha economicamente racional, guardadas as propriedades medicinais de cada grupo de fármacos (MENDA, 2002).

Tendo em vista a lei de medicamentos genéricos vigente no país, este trabalho objetivou verificar o nível de conhecimento dos usuários de medicamentos entrevistados em relação aos medicamentos genéricos, a adesão dos profissionais prescritores da área de saúde à lei dos genéricos e quantificar as prescrições que solicitam a não intercambialidade dos medicamentos pelos genéricos.

\section{MATERIAL E MÉTODOS}

O estudo foi realizado em uma farmácia de dispensação no município de ToledoPR. Para avaliação da utilização dos medicamentos genéricos foram utilizados dois instrumentos de estudo:

1) Receituários médicos ou odontológicos aviados na farmácia. Foi feita análise da prescrição do medicamento genérico e se havia proibição da intercambialidade do medicamento de referência pelo medicamento genérico.

2) Questionário estruturado (Anexo I), contendo 06 perguntas sobre o medicamento genérico, analisando o conhecimento, identificação, motivo da aquisição e o acesso aos medicamentos genéricos, pelos entrevistados.

Os dados foram coletados aleatoriamente, conforme a aceitação do cliente em participar da pesquisa; no período de 15/01/07 a 05/02/07. Foram analisadas 50 prescrições, e entrevistados 50 usuários de medicamentos com aplicação de questionário.

\section{RESULTADOS E DISCUSSÃO}

Dos cinqüenta (50) receituários coletados, $70 \%$ (35) eram de consultórios médicos particulares, 18\% (9) eram do Sistema Único de Saúde (SUS) e 12\% (6) eram de cirurgiões dentistas.

Dos receituários coletados de consultórios médicos particulares (35), apenas $5,7 \%$ (02) continham identificação segundo a DCB e em $94,3 \%$ (33), os medicamentos eram identificados somente com nomes comerciais.

Dos receituários do SUS (9), sendo apenas 22,2\% (2) conforme DCB, $44,5 \%$ (4) com nomes comerciais e 33,3\% (3) mistas.

Dos receituários de cirurgiões dentistas (6), 66,7\% (4) eram descritas segundo DCB e $33,3 \%$ (2) com nomes comerciais. Ver resultados na Tabela 1.

TABELA 1. IDENTIFICAÇÃO DO MEDICAMENTO NO RECEITUÁRIO SEGUNDO ORIGEM E CATEGORIA PROFISSIONAL

\begin{tabular}{|l|c|c|c|}
\hline Prescrição do medicamento & $\mathbf{7 0 , 0} \%(\mathbf{3 5})$ & $\mathbf{1 8 , 0} \%(\mathbf{9})$ & $\mathbf{1 2 , 0 \% ( 6 )}$ \\
\hline Descrição segundo a DCB & $5,7 \%(2)$ & $22,2 \%(2)$ & $66,7 \%(4)$ \\
\hline Nome comercial & $94,3 \%(33)$ & $44,5 \%(4)$ & $33,3 \%(2)$ \\
\hline DCB/Comercial & $0 \%(0)$ & $33,3 \%(3)$ & $0 \%(0)$ \\
\hline Total de receitas & $100 \%(35)$ & $100 \%(9)$ & $100 \%(6)$ \\
\hline
\end{tabular}


Verificou-se, portanto, o não cumprimento à legislação no item que diz respeito à identificação do medicamento pela Denominação Comum Brasileira (DCB), nem mesmo nos postos de saúde, onde por lei seria obrigatório. $\mathrm{O}$ trabalho, apesar de apresentar uma amostra limitada, evidencia que os dentistas cumprem melhor, mas não satisfatoriamente, as normas de prescrição de medicamentos. A importância de se usar a denominação comum para os medicamentos é uma preocupação mundial. $E$, em vários países, existem comissões voltadas para a padronização e estabelecimentos de regras de nomenclatura e tradução de termos relacionados a fármacos. No Brasil, a lista de DCB é de propriedade pública e proporciona informações únicas, concisas para os profissionais de saúde e público em geral (ANVISA, 2003).

Este estudo também destaca que o medicamento genérico é conhecido pela população investigada, e está disponível para comercialização, mostrando que $98 \%$ dos entrevistados já adquiriram medicamentos genéricos para o tratamento de saúde.

A Figura 1 apresenta o motivo que levou o usuário de medicamento à aquisição do genérico. Este estudo identificou que em $42 \%$ dos casos a orientação foi fornecida pelo farmacêutico, seguido pela prescrição médica em $26 \%$; por vontade própria em $24 \%$, por indicação de terceiros em $6 \%$ e $2 \%$ dos entrevistados nunca adquiriram medicamento genérico.

FIGURA 1. MOTIVO DE AQUISIÇÃO DE GENÉRICOS

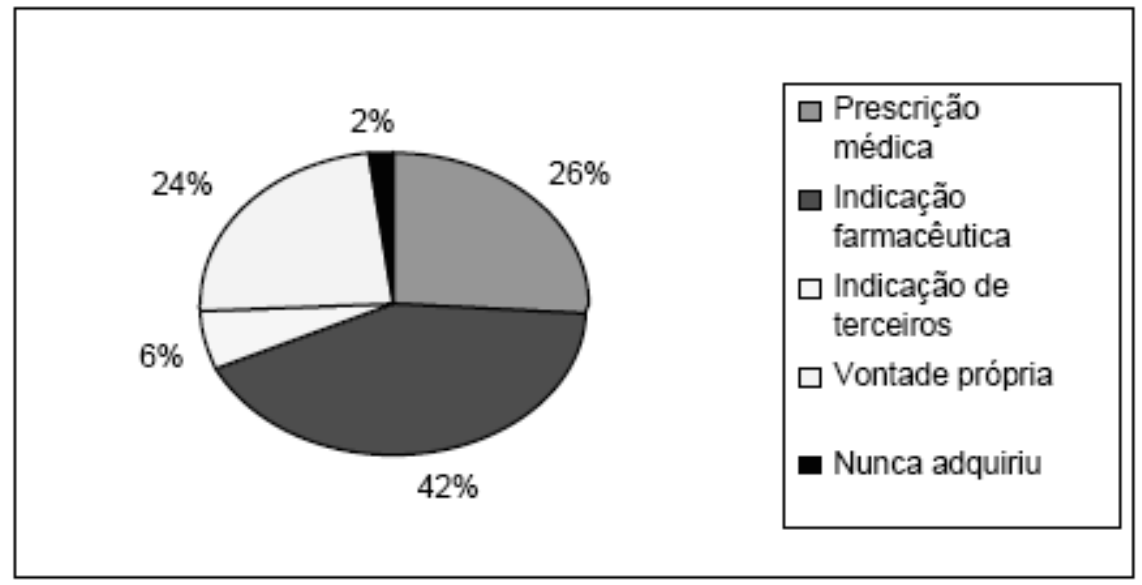

Em relação ao conhecimento sobre como identificar o medicamento genérico, $78 \%$ dos entrevistados responderam que sabem fazê-lo, diferenciando-o através da embalagem, pela presença da tarja amarela e pela letra G. Este fato evidência que a campanha de marketing do governo sobre o medicamento genérico tem produzido resultado satisfatório.

Quanto ao conhecimento da lei que prevê que o farmacêutico pode trocar um medicamento de marca prescrito pelo médico por um medicamento genérico, a pesquisa evidenciou que grande parte dos usuários (66\% dos entrevistados) sabe que o profissional pode efetuar a troca.

Não há dúvida de que, mediante a implantação da lei dos genéricos, estes medicamentos tornaram-se mais acessíveis e presentes no cotidiano da população, pois $88 \%$ dos entrevistados confirmam a facilidade na aquisição dos medicamentos 
genéricos pelo seu custo reduzido. Segundo pesquisa (VIEIRA \& ZUCCHI, 2006), o medicamento genérico foi lançado com preço $40 \%$ menor, em média, em relação ao de referência e a introdução do medicamento genérico contribuiu para a oferta de medicamento a preços menores.

A população sentiu-se beneficiada pela política de medicamentos genéricos, pois

quando questionados sobre o aumento destes nas prateleiras das farmácias e na rede pública, $90 \%$ dos entrevistados, gostariam que houvesse maior quantidade de medicamentos genéricos.

Outro ítem observado neste estudo foi a presença, em $8 \%$ do total das receitas, de carimbo solicitando a não intercambialidade dos medicamentos prescritos com marcas comerciais pelos genéricos. Como descrito em lei, no caso da não intercambialidade pelo prescritor deveria ser feita de próprio punho (BRASIL, 2002), fato não observado nas prescrições coletadas e que não impede o farmacêutico de efetuar a intercambialidade, se for de vontade do usuário do medicamento.

\section{CONSIDERAÇÕES FINAIS}

A adoção da Política Nacional de Medicamentos Genéricos pelo governo federal envolve a produção, a garantia da qualidade, a prescrição, a dispensação e o uso dos medicamentos genéricos, e é parte fundamental de uma diretriz para uso racional de medicamentos no Brasil. Para alcançar o principal objetivo - o acesso da população aos medicamentos - é fundamental a participação ativa e consciente dos profissionais responsáveis pela prescrição e dispensação dos medicamentos - médicos, dentistas e farmacêuticos (MENDA, 2002).

Se, por um lado, este estudo mostrou a aprovação e a procura por parte do usuário do medicamento pelo genérico, por outro lado, parece ser o baixo interesse dos prescritores, em facilitar o acesso dos medicamentos genéricos à população em geral. Inclusive, por parte de alguns, verificou-se a rejeição a este tipo de medicamento.

Quando se trata de medicamentos genéricos, não há como discuti-los isoladamente, pois estão inseridos na categoria médica em um contexto mais amplo em que outros temas são obrigatoriamente discutidos; inclui-se entre eles questões éticas sobre a promoção de medicamentos. O médico é o centro da atenção das ações de "marketing ético" da indústria farmacêutica em razão de sua posição, por ser o profissional real "comprador" dos medicamentos para seus pacientes, por ser detentor da capacidade técnica para tal. A política desenvolvida pela indústria farmacêutica para abordagem do médico é levada à cabo pelas companhias multinacionais ou nacionais, utilizando em sua propaganda, um percentual que representa $15 \%$ do faturamento da empresa, sendo um dos principais custos do medicamento (MENDA, 2002).

A Organização Mundial de Saúde recomenda que as listas de medicamentos essenciais e a adoção de programas de medicamentos genéricos, bioequivalentes e intercambiáveis, constituam os eixos principais das políticas de medicamentos que objetivam expandir a cobertura e assegurar o acesso da população a medicamentos eficazes e seguros, contribuindo para um mercado racional. A experiência internacional mostra que os maiores êxitos obtidos na promoção dos genéricos têm ocorrido nos países em que as ações são direcionadas para influenciar o comportamento de médi- 
cos e profissionais de saúde por meio de informações que comprovam a qualidade e a confiabilidade desses medicamentos (CREMESP \& CRF-SP, 2001). Isso aponta para a necessidade de implantação de medidas maiores de divulgação dos medicamentos genéricos nas classes dos profissionais da saúde, e que possam resultar em mudanças de maior impacto social, facilitando o acesso ao medicamento de baixo custo.

\section{REFERÊNCIAS}

ANVISA - Agência Nacional de Vigilância Sanitária. Medicamentos: denominação comum brasileira. Brasília, 2003. Disponível em: <www.anvisa.gov.br/medicamentos / dcb/apresenta. htm>. Acesso em: 2 mar. 2007 .

ANVISA- Agência Nacional de Vigilância Sanitária. Sistema de perguntas e respostas. Brasília, 2002. Disponível em: <http//www.anvisa.gov.br.faqdinamica/ index.asp? secao $=38>$. Acesso em: 15 set. 2006.

BRASIL. Ministério da Saúde. Lei n 9.787 de 10 de fevereiro de 1999. Estabelece o medicamento genérico, dispõe sobre a utilização de nomes genéricos em produtos farmacêuticos e dá outras providências. Brasília, 10 fev. 1999.

BRASIL. Ministério da Saúde. Resolução RDC n. 47 de 28 de março de 2001. Determina a obrigatoriedade do uso da tarja amarela com " $G$ " nas embalagens de medicamentos genéricos para facilitar a sua distinção. Brasília, 28 mar. 2001.

BRASIL. Ministério da Saúde. Resolução RDC n. 84 de 19 de março de 2002. Aprova O

CREMESP - CONSELHO REGIONAL DE MEDICINA DO ESTADO DE SÃO PAULO; CRF-PR - CONSELHO REGIONAL DE FARMÁCIA DO ESTADO DE SÃO PAULO. Medicamentos genéricos: informações para médicos, farmacêuticos e profissionais da saúde. São Paulo: 2001. 109 p. Disponível em: http://www.cremesp.org.br/manual lgenericos.htm. Acesso em: 23 out 2008.

MENDA, E. et al. Manual médico: medicamentos genéricos. São Paulo: Lemos Editorial, 2002. $141 \mathrm{p}$.

PIACENTINI, P. Mídia e legislação garantem sucesso dos genéricos. Revista Eletrônica de Jornalismo Científico, 2006. Disponível em: <http//www.comciencia.br / comciencia/?section $=3 \&$ noticia=182>. Acesso em: 15 set. 2006.

Regulamento Técnico para medicamentos genéricos, na prescrição, dispensação e intercambialidade. Brasília, 19 mar. 2002.

VIEIRA, F. S.; ZUCCHI, P. Diferenças de preços entre medicamentos genéricos e de referência no Brasil. Rev. Saúde Pública, São Paulo, v. 40, n. 3, 2006 